\title{
Paving the Way for Media Literacy Instruction in Preservice Teacher Education: Prospective Teachers' Levels of Media Literacy Skills ${ }^{1}$
}

\author{
Cahit Erdem \\ Dr., Afyon Kocatepe University, Turkey, cerdem@aku.edu.tr \\ Bahadır Erişti \\ Assoc. Prof., Anadolu University, Turkey, beristi@anadolu.edu.tr
}

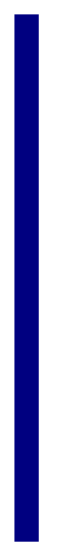

This study aims to identify prospective teachers' levels of media literacy skills. This is a mixed-type study with explanatory sequential design. In the quantitative phase, 865 prospective teachers in a state university, selected through multi-stage cluster sampling method, took Media Literacy Skills Scale. In the qualitative phase, semi-structured interviews were held with five prospective teachers. In data analysis, CFA, descriptive statistics, Mann Whitney U test, Kruskal Wallis test and descriptive analysis were used. The study reveals that prospective teachers have a medium level of media literacy skills and their levels differ significantly by their academic success and teaching programs they attend to but not by gender. The qualitative analysis also puts fort the participants lack some competencies in media literacy skills of access, analyzes, evaluate and communicate; and provides detailed descriptions as to them. This research is expected to serve for curriculum development studies with respect to media literacy instruction in preservice teacher education.

Keywords: media literacy, media literacy skills, prospective teachers, preservice teacher education, media literacy instruction

\section{INTRODUCTION}

Media literacy is among the basic skills that individuals need to possess in the twentyfirst century (Finegold \& Notabartolo, 2008; Som \& Kurt, 2012). The unprecedented advances in information and communication technologies (ICTs), and the fact that these technologies have been located in the center of people's lives require defining and managing the necessary skills to efficiently use them (Livingstone, 2003). Particularly in the current century, people are in a bombardment of information through media, and protecting oneself from this bombardment has gained significance (Potter, 2008).

\footnotetext{
${ }^{1}$ This research study was derived from Cahit ERDEM's doctoral dissertation (2018) entitled "Designing a media literacy curriculum for preservice teachers", submitted to Anadolu University, Turkey.

Citation: Erdem, C., \& Eristit, B. (2018). Paving the Way for Media Literacy Instruction in Preservice Teacher Education: Prospective Teachers' Levels of Media Literacy Skills. International Journal of Instruction, 11(4), 795-810. https://doi.org/10.12973/iji.2018.11450a
} 
Taking the fact that media messages are constructed into account, the vital importance of the case becomes evident because media culture is normally invisible and it is internalized unwittingly (Kellner \& Share, 2007). Therefore, these developments in the media culture require the individuals in the new century to acquire skills to use information efficiently, analyze information, address it critically from various perspectives, and use technologies and media tools that enable communication of information (Karaman \& Karataş, 2009). A media literate individual is an efficient media user and has a critical perspective in the interaction with media.

Teachers have the biggest role in helping individuals acquire media literacy skills. Masterman (2005, p.24) highlighted that the main responsibility of teachers is to develop children's self-confidence and critical maturity for them to be able to critically evaluate media texts they will encounter in the future. National Council for Accreditation of Teacher Education (NCATE) in the U.S.A. states in its professional standards that "These teachers understand media's influence on culture and people's actions and communication; as a result, teachers use a variety of approaches for teaching students how to construct meaning from media and non-print texts and how to compose and respond to film, video, graphic, photographic, audio, and multimedia texts" (NCATE, 2008). Teacher competencies, defined by Ministry of National Education in Turkey, include performance indicators regarding media literacy, as well. These indicators highlight that teachers need to be technology literate, make use of ICTs to share information, be a model for efficient use of technology sources and teach them.

Teachers serve as a model for their students regarding media literacy (Schwarz, 2001). Therefore, to get students acquire media literacy skills, it is a need for all teachers to be media literate. In addition, this will help them to better address students who have high level of interaction with media in daily life, to use media tools efficiently in the instruction process, to identify unharmful and inoffensive content while selecting content through the Internet, and to encourage students to express themselves through media and find solutions for social problems. Teachers can also foster critical thinking skills in children (Baker, 2010), and provide variety in the teaching process by procuring various materials for students with different learning styles (Schwarz, 2001). To this end, teachers need to acquire media literacy skills through well-structured preservice and in-service training (Recepoğlu, 2015). The need for teachers' professional development in this respect is not an option but an obligation (Fleming, 2013). Providing media literacy education in particularly pre-service teacher education programs would enrich prospective teachers in this respect. The literature highlights the need for media literacy education to be offered in education faculties (Considine, 2002; Fleming, 2013; Jolls \& Grande, 2005; Karaman \& Karataş, 2009).

The first step in providing media literacy education for prospective teachers is identifying at what level they possess these skills. This analysis would help in designing a curriculum to this end. There is research in the literature aiming to identify prospective teachers' levels of media literacy. These studies mostly examine prospective teachers' levels of media literacy in terms of various variables (Engin \& Genç, 2015; Karaman \& Karataş, 2009; Karasu \& Arıkan, 2016; Tuncer, 2013). Some of these variables include 
gender and department. Most of the studies put forth that prospective teachers' levels of media literacy do not differ by gender (Çepni, Palaz \& Ablak, 2015; Fidan, 2013; Karasu \& Arıkan, 2016; Y1lmaz \& Aladağ, 2015) but findings regarding the variable of department vary. While Engin \& Genç (2015) and Yılmaz \& Ö̈zkan (2013) report a significant difference, studies by Karasu \& Arikan (2016) and Tuncer (2013) do not report such a difference. On the other hand, it is identified that the variable of academic success is ignored in the literature.

The majority of the studies focus on a particular teaching program and they are quantitative and they mostly employ two media literacy scales. Quantitative studies based on scales are helpful to put forth the overall picture of prospective teachers' levels of media literacy; however, it is also needed to be cautious since media literacy selfevaluation scales tend to represent students' self-confidence more as opposed to their real skills (Schilder, Lockee \& Saxon, 2016).

From this point of view, to get a deeper understanding of the data derived from selfevaluation scales, mixed studies are needed in which qualitative data are obtained following quantitative data. There is not such type of study in the literature regarding prospective teachers' levels of media literacy. Furthermore, it should be noted that considering the rapid transformation in ICTs and media tools and platforms, the scales of media literacy including new media tools and platforms as well as mass media tools with a focus on creating media contents, sharing them with others, expressing oneself through media tools, being an active citizen and finding solutions to social problems should be used. The data from scales should also be supported by qualitative data. This study aims to identify prospective teachers' levels of media literacy. To this end, a selfevaluation scale and interviews were resorted to answer the research questions in the following:

1. What are prospective teachers' levels of media literacy skills?

2. Do prospective teachers' levels of media literacy skills differ by gender, department and academic success?

3. What are prospective teachers' opinions as to their media literacy skills?

\section{METHOD}

\section{Research design}

This study adopted mixed method to identify prospective teachers' levels of media literacy comprehensively and it was designed in accordance with explanatory sequential design, which involves collecting quantitative data first and then qualitative data to get a deeper understanding and quantitative data informs planning of qualitative phase and questions to be asked in that phase (Creswell, 2012). In accordance, qualitative data collection from interviews follows the implementation of a scale in this study.

\section{Participants}

\section{Participants group 1}

The population of the research consists of 2285 prospective teachers attending to education faculty of a state university in the academic year of 2016-2017. 1026 volunteering participants took the scale and data from 865 participants were included in the analysis. The participants were selected through multi-stage cluster sampling, in 
which participants are selected in two or more stages (Christensen, Johnson \& Turner, 2015; Creswell, 2012), which are departments and grade levels in this study. One group from all grade levels of each of seven teaching programs in the education faculty was involved in the study. Groups in each grade levels of the departments were selected randomly to represent variety in the population (Newby, 2014). Demographic information of participants in group 1 is provided in Table 1.

Table 1

Demographic information of participants group 1

\begin{tabular}{|c|c|c|c|c|c|c|c|c|c|}
\hline \multirow{2}{*}{$\begin{array}{l}\text { Teaching } \\
\text { Program }\end{array}$} & \multirow[b]{2}{*}{ Grade } & \multicolumn{2}{|c|}{ Gender } & \multirow[b]{2}{*}{ Total } & \multirow{2}{*}{$\begin{array}{l}\text { Teaching } \\
\text { Program }\end{array}$} & \multirow[b]{2}{*}{ Grade } & \multicolumn{2}{|c|}{ Gender } & \multirow[b]{2}{*}{ Total } \\
\hline & & Male & Female & & & & Male & Female & \\
\hline Comp. \& & 1 & 16 & 15 & 31 & Elementary & 1 & 4 & 28 & 32 \\
\hline Inst. Tech. & 2 & 15 & 12 & 27 & Maths Edu. & 2 & 9 & 35 & 44 \\
\hline \multirow[t]{3}{*}{ Edu. } & 3 & 13 & 12 & 25 & & 3 & 5 & 30 & 35 \\
\hline & 4 & 16 & 14 & 30 & & 4 & 10 & 22 & 32 \\
\hline & Total & 60 & 53 & 113 & & Total & 28 & 115 & 143 \\
\hline Elementary & 1 & 4 & 20 & 24 & Pre-school & 1 & 4 & 31 & 35 \\
\hline \multirow[t]{4}{*}{ Edu. } & 2 & 9 & 20 & 29 & Edu. & 2 & 1 & 32 & 33 \\
\hline & 3 & 3 & 22 & 25 & & 3 & 2 & 28 & 30 \\
\hline & 4 & 6 & 17 & 23 & & 4 & 2 & 30 & 32 \\
\hline & Total & 22 & 79 & 101 & & Total & 9 & 121 & 130 \\
\hline Science & 1 & 10 & 28 & 38 & Turkish & 1 & 18 & 19 & 37 \\
\hline \multirow[t]{4}{*}{ Edu. } & 2 & 9 & 28 & 37 & Edu. & 2 & 12 & 22 & 34 \\
\hline & 3 & 4 & 26 & 30 & & 3 & 6 & 30 & 36 \\
\hline & 4 & 8 & 23 & 31 & & 4 & 8 & 22 & 30 \\
\hline & Total & 31 & 105 & 136 & & Total & 44 & 93 & 137 \\
\hline Social & 1 & 12 & 17 & 29 & Total & 1 & 68 & 158 & 226 \\
\hline Studies & 2 & 9 & 16 & 25 & & 2 & 64 & 165 & 229 \\
\hline \multirow[t]{3}{*}{ Edu. } & 3 & 13 & 12 & 25 & & 3 & 46 & 160 & 206 \\
\hline & 4 & 12 & 14 & 26 & & 4 & 62 & 142 & 204 \\
\hline & Total & 46 & 59 & 105 & & Total & 240 & 625 & 865 \\
\hline
\end{tabular}

Participants group 2

Semi-structured interviews were held with five volunteering prospective teachers attending to different teaching programs at various grade levels. The number of the participants is five due to limited volunteering prospective teachers. Data saturation has been reached, though. Participants were provided with an interview consent form explaining them the aim of the study and their rights as participants. Five prospective teachers' demographic information is given in Table 2.

Table 2

Demographic information of participants group 2

\begin{tabular}{lllll}
\hline Participant & Program & Grade & Gender & GPA \\
\hline P. Teacher 1 & Elem. Math. Edu. & Second & Male & 2.50 \\
P. Teacher 2 & Pre-school Edu. & Third & Female & 3.20 \\
P. Teacher 3 & Elementary Edu. & Second & Male & 2.90 \\
P. Teacher 4 & Social Studies Edu. & First & Male & 2.88 \\
P. Teacher 5 & Turkish Edu. & Second & Female & 3.0 \\
\hline
\end{tabular}

\section{Data Collection Instruments and Data Analysis}

In the quantitative phase, "Media Literacy Skills Scale' (MLSS) (Erişti \& Erdem, 2017) was used. This scale is a 5-point Likert-type scale and consists of 45 items gathered 
under factors of access (11 items), analyze (15 items), evaluate ( 7 items) and communicate (12 items). It was stated in the original study that the scale and the theoretical model showed a fit between good and acceptable, and Cronbach alpha value for the total of the scale was .919 and Cronbach alpha values for the factors were .768, $.833, .720$ and .838 respectively (Erişti \& Erdem, 2017).

Validity and reliability studies were repeated with the new sample and confirmatory factor analysis was carried out to put forth construct validity of the scale. The ratio of the degree of freedom to chi-square showed a medium level fit $(\chi 2 / \mathrm{df}=3.35)$. GFI (.96), AGFI (.96), NFI (.96), NNFI (.98), CFI (.98), RMSEA (.052), RMR (.041) and SRMR (.048) showed perfect fit while PGFI (.87) showed a good fit according to criteria of Çokluk, Şekercioğlu \& Büyüköztürk (2012). Reliability value of the scale was calculated as $\alpha=.919$, which shows a very high level of reliability (Özdamar, 2011). This value is $783, .834, .736$ and .840 for the factors respectively. Following CFA, the data derived from scale implementation was analyzed through descriptive statistics and other tests. Mann Whitney U test was used for testing the difference by gender and Kruskal Wallis test was used for testing the difference by department and academic success.

In the qualitative phase, five prospective teachers were interviewed and a semistructured interview form was used. This form consists of questions and sub-questions about prospective teachers' opinions as to their media literacy skills. Interview form was evaluated and revised by a specialist for validity. Before implementation, a pilot interview was held with another participant. The data were analyzed through descriptive analysis method. For the coherence and credibility of the analysis, it was carried out with the researchers and participant confirmation was held with the findings.

\section{FINDINGS}

\section{Prospective teachers' levels of media literacy skills}

Prospective teachers' mean scores and standard deviations of the total of the scale and each factor are provided in Table 3.

Table 3

Mean scores of the total and factors of the scale

\begin{tabular}{lllll}
\hline & $\mathrm{N}$ & Mean & Sd & Max Score \\
\hline Access & 865 & $39.6844(3.60)$ & .51352 & 55 \\
Analyze & 865 & $53.7017(3.58)$ & .48521 & 75 \\
Evaluate & 865 & $25.9688(3.70)$ & .56172 & 35 \\
Communicate & 865 & $42.9757(3.58)$ & .58302 & 60 \\
Total & 865 & $162.3306(3.60)$ & .43338 & 225 \\
\hline
\end{tabular}

Prospective teachers' mean score obtained from MLSS was calculated as 162.33 (3.60). Maximum score to get from this scale is 225 . As for the factors, the lowest mean scores obtained by the prospective teachers are analyze and communicate (3.58). The highest mean score belongs to evaluate factor (3.70).

\section{Difference in prospective teachers' levels of media literacy skills by gender}

Mann Whitney U test was carried out to identify if prospective teachers' levels of media literacy skills differ by gender as data didn't show a normal distribution (kurtosis=1.011, skewness $=-0.996$ ). Prospective teachers' mean scores by gender are given in Table 4. 
Table 4

Mean scores by gender

\begin{tabular}{lll}
\hline Gender & Mean & $\mathrm{p}$ \\
\hline Male & 162.69 & .711 \\
Female & 162.19 & \\
\hline
\end{tabular}

Mean scores of prospective teachers do not differ significantly by gender ( $>$.05). Means of the two groups are very close to each other. This finding asserts that gender is not a significant variable on prospective teachers' levels of media literacy skills.

Difference in prospective teachers' levels of media literacy skills by academic success

Kruskal-Wallis test was carried out to identify difference by academic success as data didn't show normal distribution (kurtosis $=-1.309$, skewness $=0.490$ ). Prospective teachers' mean scores by academic success are given in Table 5.

Table 5

Mean scores by academic success

\begin{tabular}{lll}
\hline A. Success & Mean & $\mathrm{p}$ \\
\hline Conditional pass (1.5-2.0) & 155,60 & .007 \\
Pass (2.0-2.5) & 160,63 & \\
Medium (2.5-3.0) & 163,94 & \\
Good (3.0-3.5) & 164,74 & \\
Very good (3.5-4.00) & 160 & \\
Not specified & 159,66 & \\
\hline
\end{tabular}

The analysis reveals that there is a statistically significant difference between prospective teachers' levels of media literacy skills and academic success $(p<.05)$. The students of 'good' academic success have the highest mean score. Groups of 'medium', 'pass', 'very good' and 'conditional pass' follow it. Except for prospective teachers with 'very good' academic success, their levels of media literacy skills increase as their academic success increases.

\section{Difference in prospective teachers' levels of media literacy skills by teaching programs}

Kruskal-Wallis test was carried out to identify whether participants' levels of media literacy skills differ by teaching programs as data didn't show normal distribution (kurtosis $=-1.224$, skewness $=-0.109)$, which is given in Table 6 .

Table 6

Mean scores by teaching programs

\begin{tabular}{lll}
\hline T. Programs & Mean & $\mathrm{p}$ \\
\hline Comp. \& Inst. Tech. Edu. & 165.80 & .002 \\
Elementary Edu. & 157.72 & \\
Science Edu. & 163.77 & \\
Social Studies Edu. & 163.34 & \\
Elementary Math Edu. & 157.73 & \\
Pre-school Edu. & 165.05 & \\
Turkish Edu. & 162.86 & \\
\hline
\end{tabular}


The analysis puts forth that prospective teachers' levels of media literacy skills differ significantly by the teaching programs they attend to $(\mathrm{p}<.05)$. The groups with the highest means are Comp. \& Inst. Tech. Education and Pre-school Education. The groups with the lowest means are Elementary Education and Elementary Math Education. Mann Whitney U test was carried out to identify difference in which groups were statistically significant. The pairwise comparison revealed a statistically significant difference between mean scores of Comp. \& Inst. Tech. Education and Elementary Math Education, and between Pre-school Education and Elementary Math Education ( $\mathrm{p}=.00)$.

\section{Prospective teachers' opinions regarding their own media literacy skills}

Questions on media literacy skills were asked to participants to elicit at what level they have media literacy skills. The responses were analyzed under four themes, which are basic media literacy skills; access, analyze, evaluate and communicate. Themes and subthemes are explained respectively.

\section{Theme 1: Access}

\section{Technical competency}

Media tools used mostly by participants are smart phones and computers. Except for Prospective Teacher-5, all participants stated they could efficiently use these two media tools. Yet, Prospective Teacher-5 highlighted that she didn't have a good command of particularly computers and said: "Technically, I don't have any information on computers but I can use smart phones with $75 \%$ efficiency".

Participants stated that they could download, store and retrieve data and take precautions in order not to lose data; however, they only back up data on only usb drives. None of them used cloud storing, for instance. Prospective Teacher-5 stated this as follows: "I have files in my flash drive that I store data as to my teaching field; however, sometimes they get deleted and I can't retrieve them. Because I don't know how to. They say there is cloud storing or something but I don't know it because it doesn't arouse my interest."

\section{Information searching platforms}

Most of the participants use Google as a search engine to reach information. Only, Prospective Teacher-5 use Yandex instead of Google, as she explained: "Yandex has the feature to open a new tab, which doesn't exist in Google. It opens what you click as a new tab and Yandex is kept in the backplane, which I like. That's why I am using it." In addition, it was revealed that Prospective Teachers 3,4 and 5 can't differentiate between a search engine and web browser. Prospective Teacher-1 didn't know any search engines other than Google and Prospective Teacher-2 knew Yandex as well as Google but didn't prefer to use it.

Methods of searching information

It was found out that while searching for information, participants generally wrote keywords on Google and chose one of the first few options, mostly the first one. Here is how Prospective Teacher-1 does it: "I directly write on Google and choose the one that suits to my aim. Generally, I check the first one, if not move on to second and third." 
It is observed that participants tend to select the first search result as they think that the first ones are more reliable and preferred by everyone. They think that the list of search results is created based on only the mostly used websites. When told that they may be created with commercial aims, Prospective Teacher-4 answered as follows: "I don't think so. I mean, Google makes it reliably, it doesn't allow such kind of things". Besides, they only use a few keywords while searching. They don't know methods of limiting and filtering search contents. For instance, they stated that they didn't know how and why quotation marks or plus sign were used.

\section{Theme 2: Analyze}

Method of analysis; The participants stated that they analyzed media contents in two ways. The first way involves comparing media contents with previously acquired information and the second one includes comparing them with other sources. However, comparing with other sources all the time and doing this for all contents are not possible. Then it is important to analyze media content based on its own dynamics; however, it is identified that the participants have problems with this. Prospective Teacher-1's response puts forth this fact: "I can analyze based on what I know rather than the content itself. I can't decide whether it is true or false then".

Author; The participants reported they checked author or institution of the media contents; however, they acknowledged that they had never searched for an author or a media institution before. Prospective Teacher-4 indicated that he obtained information about authors in media or media institutions from what he heard from his social circle. Only Prospective Teacher-3 stated that he did some sort of search but he failed in this effort. He explained it as follows: "Some time ago, I pondered a lot on these issues. I was checking for who owned televisions, news websites and so on, particularly ones which were closed. But there are too many of them so it is hard to follow all of them. After some point, you quit and say I can't follow".

Purpose; The participants reported analyzing the purpose of media contents by checking whether it is biased or objective, or which side it defends. Prospective Teacher-2 explained how he decided on this as: "... I compare it with what I know and I prefer to ask about it to other people".

Prospective Teacher- 2 confirmed he labeled contents as biased if it is different from his point of view. On the other hand, Prospective Teacher-4 was asked if he questioned the purpose of the content while watching a video, reading news or surfing on social media and he reported he never did. It was concluded that the participants didn't follow a particular method for checking the purpose of media contents; they generally compared it with what they knew; they labeled contents as biased if it didn't fit to their views; they were contended with the apparent purpose. They don't try to reveal the main purpose of media contents by posing questions to them.

Design properties; The responses of the participants suggest that participants do not perform a detailed analysis regarding design properties of media contents. Prospective Teacher 2 told she paid attention to design properties of contents; yet, when provided with examples such as why bigger type sizes are used in a newspaper, she figured she 
didn't pay attention to details. Prospective Teacher-4 told he didn't pay attention to design properties of the contents, too.

Audience; Prospective Teacher-1 and 2 stated they paid attention to whom the media contents target. Prospective Teacher- 3 thinks that the audience is mostly obvious in media contents. Similarly, Prospective Teacher-4 answered the question whether he questioned the audience as follows: "Well, I guess it is explicitly told in the text". The fact that prospective teachers find the explicitly given elements as sufficient indicates that they don't question who is the targeted audience of media text. In the same vein, Prospective Teacher-5 thinks that it is overt in opinion texts however she didn't pay attention to this detail in daily news or other contents.

Feelings; The participants stated that they could identify the feelings tried to be transmitted only if they are overt. Prospective Teacher-3 indicated that he could rarely recognize channeling carried out through the feelings transmitted besides what is told in the contents. Prospective Teacher- 5 is aware that some feelings are transmitted through media messages but she seems not to be questioning them sufficiently as she stated: "I believe that some texs are to provoke while some are for passivation but I don't think about this for individual messages".

Manipulation, agitation; The participants stated that they could recognize manipulation and agitation elements in media messages. Prospective Teacher- 2 thinks she can recognize those elements but sometimes her feelings dominate. Prospective Teacher- 4 stated he tried not to believe in such messages without checking its trueness. Prospective Teacher-5 pointed out that there was too much agitation in media and she hated it. With an example, she stated that she didn't find the celebrities sincere and saw all messages of this kind as agitation: "I have this habit that I believe all of them are agitation. Maybe some of them are real but I don't like any of them and think that all are agitation".

Responses; Although the participants are strict users of social media, they don't usually create positive or negative responses. When they do, they reported using rational responses as opposed to emotional responses. They were particularly asked if they responded to offensive contents and it was observed that they suppressed their emotional responses. Prospective Teacher-1 states: "I may write something as a response to provide a rational explanation or change his/her mind rather than getting angry or insulting". Prospective Teacher-5 stated that she didn't always respond but when she did, it depended on the respondent. That prospective teachers prefer rational responses to emotional ones seems positive; however, they avoid giving responses although they constantly use social media, which poses a significant finding.

Content type; Four of the participants stated that they could determine what type of contents the media channels are sharing. They explained that they could do because it is generally overt. On the other hand, Prospective Teacher-5 stated she never paid attention to content type. She said: "Frankly, I realize I haven't thought about it so far. I don't check whether it is a humor website or news website. I perceive the first search result as good because everyone else is using it". 
Media structure; The participants were asked what they knew about the media industry and media structure. All participants stated they didn't know about media structure and operation processes.

\section{Theme 3: Evaluate}

Data security; It was identified that the precautions taken by the participants were limited to using passwords. Prospective Teacher-3 stated he configured who could see what he shared on social media accounts. Prospective Teacher-5 reported she lacked knowledge about this issue by saying: "I do nothing. Even the Internet I am using is easily accessible. I mean everyone can see what I do on the Internet. I know this but I have no idea what I can do about it. How can I protect myself? I don't even use online shopping".

Regarding data security, they don't either take precautions for hindering tracking of personal data. For instance, Prospective Teacher-1 stated he didn't do anything on this issue. Prospective Teacher-2 said he didn't care about applications on smart phones or location information. In addition, four of them knew that the ads on website come up based on previous website or search history but they didn't know how to prevent it. Prospective Teacher-4 had no idea about the issue.

Protection from harmful content; The participants reported that they took security protection by not using websites they don't trust. Prospective Teacher-1 stated: "If there are such websites or channels, I close them or change the channel. Regarding viruses, I don't use websites that I don't trust'. Prospective Teacher-2 registers a complaint if encountered with harmful content. When asked what they did in case they encountered a harmful content and could not close it although they didn't enter the website deliberately, Prospective Teacher-3 and 4 told they didn't know what to do in such a case. Prospective Teacher-5's response outlines their level: "There are sometimes fake ads because of a virus on the phone. Then I am a bit nervous. (Researcher: What do you do then?) I close it. Even if I search for this issue... There is so much information that I am fed up with it and I don't want to search for it".

Evaluation principles; Four of the participants stated they paid attention to whether media content involved violence and sexuality, whether it conformed to their own views, moral principles of the society and language rules while evaluating media messages. Prospective Teacher-1 told that if a message included violence or sexuality, he closed it immediately. Prospective Teacher-2 checks for honesty and congruence with moral principles. Prospective Teacher- 4 stated he didn't care about ethical principles in evaluating messages. He said: "I don't think there is inconveniency in offending people through media messages" when asked if he paid attention if the message is offending a person.

Variety in media sources; The participants were asked about variety in their interaction with media. It was identified that they mostly followed the same media channels or sources. Prospective Teacher-1 stated he used two or three sources of television channels and websites. They are close to each other regarding world-view. This case is similar for Prospective Teacher-2 and 5. Yet, more importantly, Prospective Teacher-5 
stated she didn't know about their worldviews or perspectives. In addition, they were also asked whether their analysis process was affected if information came from a source that they trusted. Prospective Teacher-2,4 and 5 stated they question the contents less in those cases. Prospective Teacher- 1 and 3 stated they questioned contents even if it came from a trusted source.

\section{Theme 4: Communicate}

Expressing oneself through media; Prospective Teacher-1,3 and 5 reported they didn't use media tools to express themselves even though they are strict social media users. They can be named as passive social media users. They follow what other people share but they don't create new content and share it. Prospective Teacher-1 even stated he had never shared an entry in social media so far. Prospective Teacher-3 shared only on important days like memorial days. The reason why they don't share contents is not about their lack of competency in creating images, videos or texts, but it is about their perspective towards new media.

Ethical principles; The participants were asked if they conformed to ethical principles while sharing contents on new media and what they did when confronted with an ethical violation. The participants pay attention to moral rules and having permission when sharing content. Prospective Teacher- 2 and 4 stated they conformed to moral rules when creating and sharing content while Prospective Teacher- 3 and 5 stated they cared about having permission.

When confronted with an ethical violation, they react differently. Prospective Teacher-1 ignores those contents while Prospective Teacher-2 registers a complaint. Reactions of Prospective Teacher-3 and 5 depend on their relationship with the owner of the content. Prospective Teacher-4 has a passive reaction, as well: "I don't tell anything to him/her, I don't react but I don't follow his/her page again".

Digital campaigns; This part is about finding solutions to social problems and digital campaign is a good example for that. It was identified that the participants didn't get into action in solving social problems through media. None of them started a digital campaign before. Prospective Teacher-4 and 5 didn't even hear of digital campaigns. The questions were not limited to digital campaigns. Using e-mails and other platforms to get contact with local municipalities, for instance, were also asked but none of them did them. Prospective Teacher- 1 and 3 reported participating in a digital campaign once and Prospective Teacher-2 stated she paid attention to such received e-mails. Prospective Teacher-3's experience is as follows: "There was a problem with buses last year. My friends texted me to participate to the campaign. It was affecting me, too. It was about the price or itinerary. I signed for that".

Media security; The participants were asked if media was an appropriate and secure platform for people to express themselves. They think that media is an appropriate platform for this but it needs to be used properly. Yet, not all of them consider media as a secure platform. Prospective Teacher-1 states: "It can be used for spreading news securely. Or for research purposes. However, it is used to imbed bad things to people's subconscious". However, Prospective Teacher-4 and 5 thinks it is quite secure and 
Prospective Teacher-5 points out to a different issue: "Formerly, before social media, people had some fears. Even when expressing an opinion, s/he watched out other people because you are in a physical setting and they can batter you or you can do that but on social media such a physical violence is not possible. In the worst case, you close the Internet".

The participants do not consider media, particularly social media, as secure although they accept it as a way for people to express themselves. Prospective Teacher-4 attributes it to hackers online. Only Prospective Teacher- 2 and 4 reported expressing themselves through media.

\section{DISCUSSION AND CONCLUSION}

This study aims to identify prospective teachers' levels of media literacy skills based on a self-evaluation scale (MLSS) and interviews. While the quantitative phase of the study revealed the general picture of the prospective teachers regarding their media literacy skills, the qualitative phase elicited in-depth data. The analysis of MLSS put forth that the participating prospective teachers' mean score is 162.33 (3.60), which can be regarded as medium level considering a maximum score of 225. This finding is in line with Som \& Kurt (2012), Karasu \& Arıkan (2016) and Yılmaz \& Aladağ (2015). Mean scores of prospective teachers in other studies (Engin \& Genç, 2015; Fidan, 2013; Yllmaz \& Özkan, 2013) are also close to this study. There are also studies reporting relatively higher levels (Çepni, Palaz \& Ablak, 2015; Uslu, Yazıcı \& Çetin, 2016). On the other hand, it should be noted that students at CITE raise mean scores. This finding suggests that prospective teachers need media literacy education to serve as a model for their students and teach them these skills.

Mean scores of the factors indicate that this need is further in the factors of analyze and communicate. This also coincides with the findings in the literature. One of the factors of a widely used scale in the literature (Karaman \& Karataş, 2009) is analyzing and being able to react. In the studies regarding prospective teachers, this factor had the lowest mean score in the studies by Tuncer (2013), Karaman \& Karataş (2009) and Engin \& Genç (2015). This result indicates that prospective teachers have problems in analyzing media contents and reacting by creating new media contents.

Whether levels of prospective teachers differed by gender, academic success and teaching programs were also aimed in this study. It was found out that prospective teachers' levels of media literacy didn't differ by gender, which is in line with most of the studies in the literature (Fidan, 2013; Karasu \& Arıkan, 2016; Sarsar \& Engin, 2015; Som \& Kurt, 2012; Yilmaz \& Aladağ, 2015). A difference in favor of females was found in Tuncer (2013) and a difference in favor of males was found in Uslu, Yazıcı \& Çetin (2016). The findings of this study and most of the research suggest that gender is not a significant variable regarding prospective teachers' media literacy skills.

Prospective teachers' levels of media literacy skills differ by their teaching programs, which is in line with Yllmaz \& Özkan (2013) and Engin \& Genç (2015) but not with Tuncer (2013) and Karasu \& Arıkan (2016). The findings of this study indicate that the highest mean scores belong to prospective teachers at CITE and Pre-school Education departments. This result for CITE is predictable since students in this department work 
in high interaction with media tools; however, the high mean score of Pre-school Education is an important finding. In the interviews, one of the participants in Preschool education program stated one of their instructors held media literacy conferences for them, which may account for this case.

Prospective teachers' levels of media literacy skills differ by their academic success significantly. It is revealed that their levels of media literacy skills increase in direct proportion to academic success, except for participants with 'very good' academic success, whose mean scores are lower than participants with 'medium' and 'good' academic success. It can be deduced that prospective teachers with a GPA over 3.50 may have more realistic perceptions regarding their media literacy skills. They may have evaluated themselves more realistically as they are expected to have high meta-cognitive level. Lack of a student with 'very good' academic success in the qualitative phase is a limitation of this study. Studies in the literature haven't tested the difference between levels of media literacy and academic success.

The qualitative phase of the study included interviews with five prospective teachers on their media literacy skills, analyzed in four main corresponding themes and subthemes. Regarding the skill of 'access', it was found out that the participants experienced technical problems; however, a media literate individual needs to use media technologies efficiently to access, record, retrieve and share contents (Bachmair \& Bazalgette, 2007). With respect to searching information, participants mostly use only Google, do not know methods of filtering search results and mostly choose among the first few results. It is important for people to understand symbols and techniques in media, to access information through various sources (Hobbs \& Moore, 2013; Pérez Tornero, Celot \& Varis, 2007; Thoman \& Jolls, 2005) by developing strategies with regard to knowing and using various databases and search engines and filtering results (Şahin, 2014).

Regarding the theme of 'analyze', it was identified that the participants mostly resorted to compare media contents with their previous knowledge and sometimes other sources. Though this is an important strategy (Thoman \& Jolls, 2005), it is not possible all the time, which highlights the need to analyze the content based on its own elements. Participants had problems in doing so; however, they are expected to divide messages into meaningful units (Kellner, 2001), examine contents' form and sequence (Jolls, 2008), use strategies like comparing, reason-result, truth/opinion (Thoman \& Jolls, 2005) and thereby examine the elements of a media message thoroughly (Potter, 2008), which can be listed as author, purpose, form, content and audience. It was found out that the participants lacked competency in identifying and searching for the author of media messages, determining the real purpose of the message besides the overt one, paying attention to design properties and their effects on the meaning, questioning the targeted audience and subconsciously transmitted feelings in a media message. These findings reveal the need for media literacy education, particularly in the 'analyze' score, which also had the lowest mean in the scale data.

Enabling personal security and protecting from unwelcome and harmful contents are quite important competencies for media literacy (Bachmair \& Bazalgette, 2007). The participants reported their precautions were limited to using passwords and configuring 
privacy settings on social media. They lack in security dimension. In addition, they checked for violence and sexuality, congruity with their views and social norms, honesty, and language while evaluating media messages. Evaluating a media message requires comparing it to content and form of the message itself and his/her own experiences and standards (Potter, 2008; Thoman \& Jolls, 2005), ethical, moral, scientific and democratic principles (Jolls, 2008). It can be suggested that the prospective teachers are in need of guidance for evaluating media messages thoroughly.

Creating media messages and sharing them with others have become one of the foremost skills with the advent of new media. It was found out that although the participating prospective teachers were strict social media users, they tend to not to share any contents at all. This seems to stem from their perspectives rather than lack of technical competence. However, a media literate individual creates media messages for various purposes and express themselves (Hobbs \& Moore, 2013; Thoman \& Jolls, 2005). In their limited communicate activities, they reported paying attention to ethical principles and having permission; however, when confronted with an ethical violation, they mostly react passively such as closing the webpage or quit following a certain person. This passivity is also valid for digital campaigns, which are expected to solve some social problems. Media literacy requires people to act individually and cooperatively for problems in family, workplace, country and the world (Hobbs \& Moore, 2013).

This study puts forth that prospective teachers have a medium level of media literacy skills and qualitative analysis confirms this finding and also reveals prospective teachers lack awareness regarding their media literacy skills. This study, as well as many other studies, highlights the need for media literacy education in preservice teacher education, which will invest in media literacy education at K-12 level. The findings of this study can be used as a springboard for designing media literacy curriculum for prospective teachers. Curriculum development needs to rest on needs analysis, which this study aims to serve for. This research unveils weaknesses and strengths of prospective teachers in a state university regarding media literacy skills. There is need for more qualitative and mixed-type studies to unveil prospective teachers' media literacy skills to contribute to curriculum development studies for teacher education in this respect.

\section{REFERENCES}

Bachmair, B. \& Bazalgette, C. (2007). The European charter for media literacy: Meaning and potential. Research in Comparative and International Education, 2(1), 8087.

Baker, F.W. (2010). Media literacy: 21st century literacy skills. In H. Hayes Jacobs (Ed.) Curriculum 21: Essential education for a changing world (p. 133-152). Alexandria: ASCD.

Christensen, L. B., Johnson, R. B. \& Turner, L. A. (2015). Research methods: Design ve analysis (Translation Ed.: Ahmet Aypay). Ankara: Anı Publishing.

Considine, D. (2002). Media literacy across the curriculum. Cable in the classroom: Thinking critically about media. Retrieved on March 26, 2016, from http://www.medialit.org/sites/default/files/551_CIC_ML_Report.pdf. 
Creswell, J. W. (2012). Educational research: planning, conducting, and evaluating quantitative and qualitative research. Boston: Pearson.

Çepni, O., Palaz, T. \& Ablak, S. (2015). Examining prospective social sciences teachers' level of media and television literacy according to different variables. International periodical for the languages, literature and history of Turkish or Turkic, 10(11), 431-446.

Çokluk, Ö., Şekercioğlu, G. \& Büyüköztürk, Ş. (2012). Multivariate statistics for social sciences: SPSS and LISREL applications. Ankara: Pegem.

Engin, G. \& Genc, S. Z. (2015). Examination on media literacy behaviours of teacher candidates: Ege University sample. The International Journal of Research in Teacher Education, 6(2), 1-10.

Erişti, B. \& Erdem, C. (2017). Development of a media literacy skills scale. Contemporary Educational Technology, 8(3), 249-267.

Fidan, M. (2013). Media literacy levels of candidate primary school teachers. Erzincan University Journal of Education Faculty, 15(2), 121-137.

Finegold, D. \& Notabartolo, A. S. (2008). 21st century competencies and their impact: an interdisciplinary literature review. Retieved on 12 October, 2017, from https://www.hewlett.org/library/21st-century-competencies-impact-interdisciplinaryliterature-review/.

Fleming, L. (2013). Expanding learning opportunities with transmedia practices: Inanimate alice as an exampler. Journal of Media Literacy Education, 5(2), 370-377.

Hobbs, R. \& Moore D. C. (2013). Discovering media literacy: Teaching digital media and popular culture in elementary schools. Thousand Oaks, CA: Corwin.

Jolls, T. (2008). Literacy for the 21 st century: an overview \& orientation guide to media literacy education. Center for Media Literacy. Retrieved on 2 January 2016 from http://medialit. org/medialitkit.html

Jolls, T. \& Grande, D. (2005). Project smartart: A case study in elementary school media literacy and arts education. Arts Education Policy Review, 107(1), 25-31.

Karaman, K. \& Karatas, A. (2009). Media literacy levels of teacher candidates. Elementary Online, 8(3), 798-808.

Karasu, M. \& Arikan, D. (2016). Investigation of relationship between habits of using social media and media literacy levels of teacher candidates. Ege Eğitim Dergisi, 17(2), 549-566.

Kellner, D. (2001). New technologies/new literacies: reconstructing education for the new millennium. International Journal of Technology and Design Education, 11, 67-81.

Kellner, D. \& Share, J. (2007). Critical media literacy, democracy and the reconstruction of education. In D. Macedo \& S. R. Steinberg (Eds.), Media Literacy: A reader (pp.3-23) New York: Peter Lang Publishing. 
Livingstone, S. (2003). The changing nature and uses of media literacy. MEDIA@LSE Electronic Working Papers. 4.

Masterman, L. (2005). Teaching the media. Taylor \& Francis e-Library.

National Council for the Accreditation of Teacher Education. (2008). Professional standards for the accreditation of teacher preparation institutions. Retrieved from http://www.ncate.org/LinkClick.aspx?fileticket=nX43fwKc4Ak\%3d\&tabid=474 on March 28, 2016.

Newby, P. (2014). Research methods for education. Abingdon: Routledge.

Özdamar, K. (2011). Statistical data analysis with package programs. Eskisehir: Kaan Kitabevi.

Pérez Tornero, J. M., Celot P. \& Varis T. (2007). Current trends and approaches to media literacy in Europe. Brussels: European Commission.

Potter, W. J. (2008). Media literacy. Thousand Oaks, CA: Sage.

Recepoğlu, E. (2015). The importance of media literacy education in the process of teacher training in higher education. The International Journal of Social Sciences, 40(1).

Sarsar, F. \& Engin, G. (2015). Investigation of the media literacy level of primary school teacher candidates. Ege Journal of Education, 16(1), 165-176.

Schilder, E. A., Lockee, B. B. \& Saxon, D. P. (2016). The issues and challanges of assessing media literacy education. The Journal of Media Literacy Education, 8(1), 32-48.

Som, S. \& Kurt, A. A. (2012). Media literacy levels of students attending the department of computer education and instructional technologies. Anadolu Journal of Educational Sciences International, 2(1), 104-119.

Schwarz, G. (2001). The role of media literacy in teacher education. Teacher Education Quarterly, 28(2), 111-119.

Şahin, A. (2014). Elestirel medya okuryazarligi [Critical media literacy]. Ankara: Ani.

Thoman, E. \& Jolls, T. (2005). Literacy for the 21 st century: An overview \& orientation guide to media literacy education. CML Media Lit Kit. Retrieved on 5 January 2016 from http://www.medialit.org/sites/default/files/mlk/01_MLKorientation.pdf

Tuncer, A. (2013). Media literacy levels of education faculty students (Izmir case). Unpublished Master Thesis. İzmir: Ege University, Institute of Social Sciences.

Uslu, S., Yazıc1, K. \& Çetin, M. (2016). Media li,teracy levels of social studies preservice teachers. Adlyaman University Journal of Institute of Social Sciences, 8(23), 756-778.

Yllmaz, E. \& Aladağ, S. (2015). Relationship between primary school teaching prospective teachers' habits of reading periodical publications and media literacy. Uşak University Journal of Social Sciences, 8(4), 1-15.

Yılmaz, Ö. ve Özkan, B. (2013). Comparison of media literacy levels of prospective teachers at computers and instructional technologies and pre-school education departments.Electronic Journal of Vocational Colleges, 3(1), 178-183. 